\title{
Health literacy and health seeking behavior among older men in a middle-income nation
}

\author{
This article was published in the following Dove Press journal: \\ Patient Related Outcome Measures \\ 25 May 2010 \\ Number of times this article has been viewed
}

\author{
Paul A Bourne' \\ Chloe Morris' \\ Christopher AD Charles ${ }^{2}$ \\ Denise Eldemire-Shearer ${ }^{\prime}$ \\ Maureen D Kerr-Campbell ${ }^{3}$ \\ Tazhmoye V Crawford ${ }^{4}$ \\ 'Department of Community Health \\ and Psychiatry, ${ }^{4}$ Basic Medical \\ Sciences, Faculty of Medical Sciences, \\ The University of the West Indies, \\ Mona, Kingston, Jamaica; ${ }^{2}$ Systems \\ Development Unit, Main Library, \\ Faculty of Humanities and Education, \\ The University of the West Indies, \\ Mona, Jamaica; ${ }^{3}$ King Graduate School, \\ Monroe College, 2375 Jerome Avenue, \\ Bronx, New York 10468 and Center \\ for Victim Support, Harlem Hospital \\ Center, New York, USA
}

\begin{abstract}
Health literacy is a measure of the patient's ability to read, comprehend and act on medical instructions. This research article examines health literacy and health-seeking behaviors among elderly men in Jamaica, in order to inform health policy. This is a descriptive cross-sectional study. A 133-item questionnaire was administered to a random sample of 2,000 men, 55 years and older, in St Catherine, Jamaica. In this study, 56.9\% of urban and $44.5 \%$ of rural residents were health literate. Only $34.0 \%$ of participants purchased medications prescribed by the medical doctor and $19.8 \%$ were currently smoking. Despite the reported good self-related health status (74.4\%) and high cognitive functionality (94.1\%) of the older men, only $7.9 \%$ sought medical care outside of experiencing illnesses. Thirty-seven percent of rural participants sought medical care when they were ill compared with $31.9 \%$ of their urban counterparts. Thirty-four percent of the participants took the medication as prescribed by the medical doctor; $43 \%$ self-reported being diagnosed with cancers such as prostate and colorectal in the last 6 months, 9.6\% with hypertension, 5.3\% with heart disease, 5.3\% with benign prostatic hyperplasia, 5.3\% with diabetes mellitus, and 3.8\% with kidney/bladder problems. Approximately $14 \%$ and $24 \%$ of the participants indicated that they were unaware of the signs and symptoms of hypertension and diabetes mellitus, respectively. The elderly men displayed low health literacy and poor health-seeking behavior. These findings can be used to guide the formulation of health policies and intervention programs for elderly men in Jamaica.
\end{abstract}

Keywords: health literacy, health status, lifestyle practices, older men, health-seeking behavior

\section{Introduction}

Jamaica is a developing Caribbean country that is situated in the Northern part of the Caribbean and spans an area of 4,411 square miles. It has a population of approximately 2,692,358 million people, comprised of 1,326,907 males and 1,265,451 females. ${ }^{1}$ Eldemire $^{2}$ noted that the elderly in Jamaica represent $10 \%$ of the population, and that they are for the most part mentally competent and physically independent. With a calculated life expectancy of 75.5 years, ${ }^{3}$ the burden on the health care system can be expected to increase. The epidemiologic transition in the Caribbean over the last 40 years has produced an epidemic of lifestyle-related chronic noncommunicable diseases. ${ }^{4}$ Among these are obesity, diabetes mellitus, and hypertension, along with such complications as stroke, heart disease, and amputations. ${ }^{4}$ Cardiovascular disease is by far the leading cause of death at older ages in developing countries, although the impact of communicable diseases remains considerable. ${ }^{5}$ One comprehensive analysis attributes nearly 46 percent of all deaths among females aged 60 and over in developing
Correspondence: Paul Andrew Bourne Department of Community Health Statistics, Faculty of Medical Sciences, University of the West Indies, Mona Campus, Kingston, Jamaica, West Indies Tel + 8764576990

Email paulbournel@yahoo.com 
countries in the early 1990 s to cardiovascular disease, while the corresponding figure for older males is 42 percent. $^{5}$

Health literacy is defined as the extent to which people have the capacity to obtain basic health information, which they are able to process and understand so that they can make informed decisions about their health. ${ }^{6}$ Health literacy is crucial if patients are to benefit from health care. People who cannot read or understand the words used to describe health problems, diagnostic tests, medications and directions for care may experience confusion in negotiating the health care system, and are significantly handicapped in the tasks of self-care or caring for family members. ${ }^{7}$ A significant statistical relationship was found between functional health literacy and the quantitative components of general functional literacy, prose and document. ${ }^{8}$

Just under $36 \%$ of the variance in the scores of the general context numeracy, and $26 \%$ of the variance in the scores of health context numeracy among independently functioning older adults, were predicted by the education they attained, their prose health literacy and their anxiety about mathematics. ${ }^{9}$ An interpretation of the foregoing findings also reveals that shame about an individual's condition is a troubling emotion that prevents low literate patients from interacting effectively with health care providers. ${ }^{10}$ Therefore, a person's level of education, race and available resources are crucial factors that help to determine the approaches to take in obtaining health information. The importance of these variables is evident in the findings. After controlling for the demographic factors that influence health, elderly participants without a high school diploma had lower selfrelated health status, and worse physical and mental health, compared to participants with a high school diploma. These differences were reduced by $22 \%-41 \%$ when health literacy was taken into account. In addition, blacks, other minority groups, immigrants and people with fewer resources had lower health literacy skills than members of the dominant racial group and people with more resources. ${ }^{11}$

In a study by Baker et a $1^{12}$ functional health literacy was lower among community-dwelling elderly persons after controlling for differences in their health status, their visual acuity, scores on the mini mental state examination and the frequency with which they read newspapers. Functional literacy among elderly men with prostate cancer is fostered across the life course and supported by cultural resources. These men developed critical open-mindedness from supportive home and elementary school environments, and because they had an interest in being educated and a history of reading at home. ${ }^{13}$
Health literacy is also important for dealing with a range of chronic diseases. Participants with inadequate health literacy compared to those with adequate health literacy knew much less about their chronic diseases. This finding suggests that health literacy independently influences the knowledge of disease, ${ }^{14}$ but does not always influence healthy lifestyle practices. This anomaly is evident in the finding that people were more likely to completely abstain from the use of alcohol, to have never smoked in their lives, and to be sedentary when they had inadequate health literacy compared to people who had adequate health literacy. ${ }^{15}$ Despite this anomaly, in general health literacy directly influences health outcomes. Therefore, the health status of the elderly should be improved and the cost of emergency room services reduced with an effective health literacy strategy. ${ }^{16}$

The demographic assessment for health literacy is useful for broadening the scope of research with health literacy data from national surveys. ${ }^{17}$ It is important to create a set of indicators to measure health literacy from these surveys. The developed health literacy index could be used as a composite scale, which would record the health capabilities and competence of residents in groups and communities, as well as the populations of entire countries. These variables would be linked to socioeconomic and health outcomes. In addition, this index could also quantify the outcomes of health prevention and promotion activities. ${ }^{18}$

Health literacy influences the lifestyle practices of men (55 years and older) and impacts their health. Furthermore, there is inadequate functional and health literacy among the elderly. Therefore, it is very important to understand the level of health literacy among these older men. There is a lot of information on the health literacy of the elderly in developed countries. ${ }^{19-21}$ However, there is a dearth of information on the elderly, especially males, in developing countries such as Jamaica. To bridge this knowledge gap, this study examined the health literacy of older men and their health-seeking behaviors in Jamaica. To the best of the author's knowledge, this study is the first of its kind in Jamaica and the Englishspeaking Caribbean.

\section{Methods}

This study used primary cross-sectional survey data on men 55 years and over from the parish of St Catherine in 2007. The survey was submitted and approved by the University of the West Indies Medical Faculty's Ethics Committee. A stratified multistage probability sampling technique was used to draw the sample (2,000 participants). The only inclusion-exclusion criterion for this study was men 55+ years, who were residing 
in the parish of St Catherine. A 132-item questionnaire was used to collect the data. The instrument was sub-divided into general demographic profile of the sample, good self-related health status (past and current), health-seeking behavior, retirement status, social and functional status. The overall response rate for the survey was $99 \%(n=1,983)$. Data was stored, retrieved and analyzed, using SPSS for Windows 16.0 (SPSS Inc; Chicago, IL, USA).

The Statistical Institute of Jamaica (STATIN) maintains a list of enumeration districts (EDs) or census tracts. The parish of St Catherine is divided into a number of electoral constituencies made up of a number of EDs. The one hundred and sixty-two (162) enumeration districts in the parish of St Catherine provided the sampling frame. The sample size was determined with the help of STATIN. The enumeration districts were listed and single-stage cluster sampling was used to select the sample. The enumeration districts were numbered sequentially and a selection of clusters were determined by calculating a sampling interval. From a randomly selected starting point, forty (40) enumeration districts (clusters) were subsequently selected with the probability of selection being proportional to population size. Under the advice of STATIN and having utilized the $\mathrm{C}$-survey computer software, it was decided that 50 older men in each enumeration district would be interviewed, yielding a sample size of 2,000.

The parish of St Catherine had approximately 233,052 males (preliminary census data 2001), of whom 33,674 were 55 years and older. STATIN maintains maps with enumeration districts or census tracts, which included the selected EDs and access routes, and had references to the selected site of a starting point household within each ED. The starting point was determined by randomly selecting a household with a man 55 years and older, and included the list of persons in the ED.

Where the selected household did not have an older man, the adjacent household was canvassed. Where households had a man 55+ years and he was not at home, a 'call-back' form was left indicating a proposed time when the interviewer would return. Call-back was no longer than two days after the initial visit. In households where there was more than one man 55 years and older, all were included in the survey.

The sampling frame was the parish of St Catherine. This parish was chosen because previous data and surveys by STATIN suggested that the demographic characteristics of this parish are similar to Jamaica as a whole.

\section{Measurements}

Social network was defined as self-reported involvement in church, civic organizations, social clubs and community groups. This is a binary variable, where $1=$ social network, $0=$ otherwise. The variable 'happiness' was measured based on people's self-reporting on their level of high satisfaction. It is a Likert scale question, which ranges from always-, to rarely-happy. The variable 'health status' was measured using people's self-rating of their overall health condition, which ranges from excellent to poor. The question was 'How would you rate your health today?' The response choices were (1) excellent, (2) good, (3) fair and (4) poor. In terms of education, the question for this variable was What is the highest level of education you have attained? The response choices were (1) no formal education, (2) basic school, (3) primary school/all age, (4) secondary/high/technical school, (5) vocational (ie, apprenticeship/trade), (6) diploma, (7) undergraduate degree, (8) post-graduate degree. With regard to physical exercise, the question for this variable was "Do you take time out of your regular schedule for physical exercise?" The response choices were (1) yes, or (2) no. The question on type of physical exercise was also posed. On the matter of childhood illness, the first question for this variable was 'Were you seriously ill as a child?' The response choices were (1) yes, or (2) no. The second question was 'Were you frequently ill as a child?' The response choices were (1) yes, or (2) no. If the response to either question was yes, this was coded as poor childhood health status, and if the response was no in both cases it was coded as good health status in childhood. Age group was categorized into three sub-groups. These were (1) ages 55 to 64 years, (2) ages 65 to 74 years and (3) ages 75 years and older (ie, 75 years and older).

Functional status is the summation of activities for daily living (ADL), as well as the instrumental activities of daily living (IADL). Performance of ADL was used to describe and monitor the improvement in the functional status of a person compared with his or her baseline level of functioning overtime. There are systems such as the Katz ADL tool that seek to quantify these functions and obtain a numerical value. These systems are useful for the prioritizing of care and resources. These should be seen as rough guidelines for the assessment of a patient's ability to care for himself. There were 14 items including daily activities, household chores, shopping, cooking and paying bills. The reliability of the items was very high, $\alpha=0.801$. In scoring the Katz ADL, independence on a given function is given a score of 1 , and being dependent is given a score of 0 . Total scores range from 0-14 with lower scores indicating high dependence and higher scores indicating greater independence. 
The IADL was used to assess the participants'accomplishment of activities necessary for their continued independent residence in the community. The IADL is more sensitive to subtle functional deficiencies than the ADL. In addition, the IADL differentiates among task performance, including the amount of help needed to accomplish each task. Since only men were used as participants in the study, the University of Wollongong's modified IADL functional ability scale was used to assess the IADL of men. Consequently the domains of food preparation, laundry and housekeeping were omitted in this study (with regard to the IADL for older men).

In scoring the IADL, this reflects the number of areas of impairment - that is the number of skills/domains in which subjects are dependent. Scores range from 0-5. Higher scores thus indicate greater impairment and dependence. Cohen and Holliday stated that correlation can be low/weak (0-0.39); moderate (0.40-0.69), or strong (0.7-1). ${ }^{22}$ High dependence ranges from 0 to 5.5 ; moderate dependence is from 5.6 to 9.7 and low dependence (ie, independence) ranges from 9.8 to 14 . Independence means without supervision, direction or active personal assistance. The performance on the functions can be further classified and analyzed using the format below. The classification recognizes combinations of independence/dependence with respect to particular functions reflecting the different degrees of levels of capability regarding ADL. The classification outlined below was used to further describe the functional status of men (regarding ADL). Cohen and Holliday ${ }^{22}$ correlation coefficients were used in the present study to exclude (or allow) a variable. Variables having a high correlation or a nonresponse rate in excess of $20 \%$ were excluded.

\section{Statistical analyses}

For the current study, descriptive statistics were employed to provide background information on the sample. In addition, chi-square was used to examine nonmetric variables. A $P$-value $<0.05$ (two-tailed) was used to establish statistical significance.

\section{Results}

\section{Demographic characteristics of sample}

Of the sampled participants $(n=2,000), 74.2 \%$ indicated that they had good health during their childhood; $74.4 \%$ reported good current self-related health status; $51.0 \%$ lived in rural areas; $3.5 \%$ were mostly satisfied with life; $10.4 \%$ had moderate to high functional dependence; $89.6 \%$ had low functional dependence; $21.9 \%$ were ages 75 years and older; $35.6 \%$ were ages 64.5 to 74 years and $42.6 \%$ reported ages
55 to 64 years. Fifty one percent of the participants resided in rural areas; 93\% had at most primary level education; $88 \%$ were heads of households; $25.6 \%$ were employed; $44.7 \%$ were married; single, 34.3\%; separated, 5.6\%; common-law unions, 6.8\%; widowed, 8.6\%; and 41.2\% owned their homes. In addition $94.1 \%$ had high cognitive functionality; $43.1 \%$ reported that they were depressed; $67.3 \%$ reported that they did some kind of physical exercise; $4.5 \%$ mentioned that they were happy most of the time and $71.5 \%$ claimed occasional happiness. Half of the participants indicated that they spent JS100 (US \$1.45) monthly for medical expenditure; 34\% of the participants bought their prescribed medication; $17.1 \%$ reported that they had been hospitalized since their sixth birthday and $65.8 \%$ reported that they took no medication. Of those who mentioned that they were ill during their childhood $(17.5 \%, \mathrm{n}=350), 34.9 \%$ of the instances were in relation to measles or chicken pox; $26.3 \%$ asthma; $10.0 \%$ pneumonic fever; $8.9 \%$ polio; $6.6 \%$ accident; $4.6 \%$ jaundice; $1.7 \%$ hernia, and $5.1 \%$ gastroenteritis. Twenty four percent of elderly men indicated that they were rarely happy; $40.5 \%$ said sometimes; $31.0 \%$ mentioned often, and only $4.5 \%$ reported always. Furthermore, $8.6 \%$ indicated that they were experiencing prostate cancer (self-reported); $19.8 \%$ were current smokers; and $48.2 \%$ had smoked in the past.

In response to the question 'reasons for not seeking medical care', $40.7 \%$ did not respond; $27.2 \%$ stated that they did not have a reason; $8.9 \%$ claimed financial constraints; $10.3 \%$ used home remedies; $10.4 \%$ indicated that they were not ill enough and $0.8 \%$ indicated that they did not like traditional doctors. In addition, in response to the question "What can be done to avoid medical complications?" $24.3 \%$ indicated that they had stopped drinking; $24.8 \%$ claimed that they took medication; $2.8 \%$ indicated diet; $2.0 \%$ mentioned exercise; $1.0 \%$ indicated stress avoidance and $45.4 \%$ did not respond to the question.

Fifty-four percent of participants' mothers died from other types of cancer, hypertension or diabetes mellitus, while $45 \%$ of their fathers died from the same health conditions. Almost $30 \%$ of respondents did not know the mortality of their fathers and $16 \%$ did not know the cause of death of their mothers (Figure 1). In examining the health status, health literacy and other sociodemographic characteristics by area of residence, a significant statistical association was found between health care-seeking behavior and area of residence $\left[\chi^{2}(\mathrm{df}=1)=6.40, P=0.011\right]$. Thirty-seven percent $(37.3 \%)$ of rural participants sought medical care when they were ill, as compared to $31.9 \%$ of their urban counterparts (Table 1). Based on the definition of health literacy, $56.9 \%$ of urban 


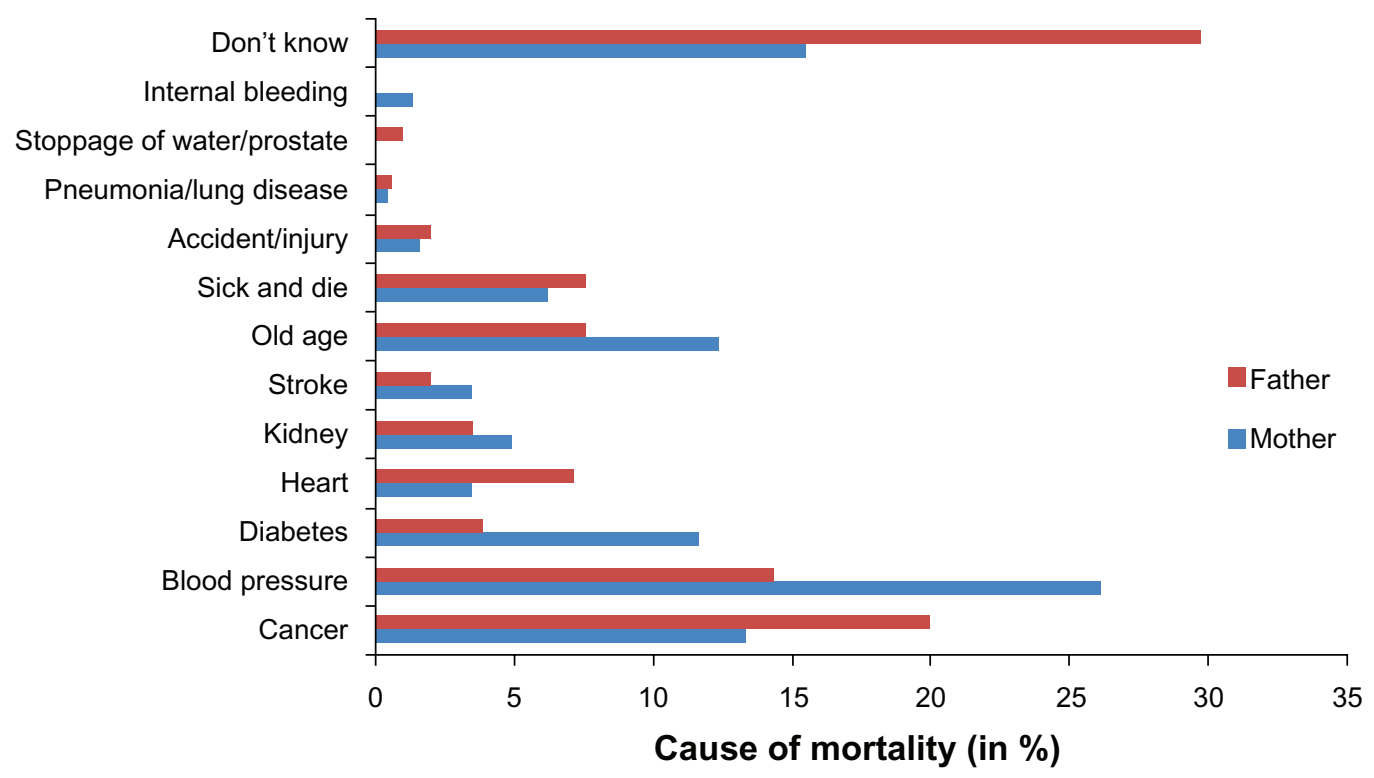

Figure I Causes of mortality of the parent(s) of participants.

Table I The examination of variables such as health status and health literacy by area of residence

\begin{tabular}{|c|c|c|c|c|}
\hline \multirow[t]{2}{*}{ Variable } & \multicolumn{2}{|c|}{ Area of residence } & \multirow[t]{2}{*}{ Total } & \multirow[t]{2}{*}{$P$} \\
\hline & Urban & Rural & & \\
\hline Health status & & & & 0.190 \\
\hline Excellent & $160(17.5)$ & $197(20.5)$ & $357(19.0)$ & \\
\hline Good & $523(57.1)$ & $515(53.7)$ & $1038(55.4)$ & \\
\hline Fair & $233(25.4)$ & $247(25.8)$ & $480(25.6)$ & \\
\hline Health literacy & & & & ${ }^{*} 0.001$ \\
\hline Physically well/Not sickness & $119(56.9)$ & $65(44.5)$ & $184(51.8)$ & \\
\hline Healthy lifestyle & $39(18.7)$ & $24(16.4)$ & $63(17.7)$ & \\
\hline Self-care & $30(14.3)$ & $32(21.9)$ & $62(17.5)$ & \\
\hline Religious activity & $9(4.3)$ & $15(10.3)$ & $24(6.8)$ & \\
\hline Psychological conditions & $7(3.4)$ & $4(2.8)$ & II (3.I) & \\
\hline Physical functioning & $5(2.4)$ & $6(4.1)$ & II (3.I) & \\
\hline Education & & & & ${ }^{*} 0.006$ \\
\hline No formal education & $103(10.5)$ & $97(9.5)$ & $200(10.0)$ & \\
\hline Primary and infant & $828(84.4)$ & $833(81.7)$ & $166 \mid(83.1)$ & \\
\hline Secondary & $33(3.4)$ & $69(6.8)$ & $102(5.1)$ & \\
\hline Tertiary & $17(1.7)$ & $20(2.0)$ & $37(1.9)$ & \\
\hline Types of medication taken & & & & ${ }^{*} 0.001$ \\
\hline No medication & $873(89.0)$ & $824(80.9)$ & $1697(84.9)$ & \\
\hline Injection & $62(6.3)$ & $112(11.0)$ & $174(8.7)$ & \\
\hline Tablets & $24(2.4)$ & $45(4.4)$ & $69(3.5)$ & \\
\hline Liquid & $14(\mathrm{l} .4)$ & $28(2.7)$ & $42(2.1)$ & \\
\hline Purchased medication & & & & 0.078 \\
\hline Yes & $318(32.4)$ & $362(35.5)$ & $680(34.0)$ & \\
\hline No & $663(67.6)$ & $657(64.5)$ & $1320(66.0)$ & \\
\hline Smoking behavior & & & & 0.251 \\
\hline Never smoked & $319(32.5)$ & $322(31.6)$ & $64 I(32.1)$ & \\
\hline In the past & $483(49.2)$ & $48 I(47.2)$ & $964(48.2)$ & \\
\hline Smoking now & $179(18.2)$ & $216(21.2)$ & $395(19.8)$ & \\
\hline Health care-seeking behavior (when ill) & & & & ${ }^{*} 0.011$ \\
\hline Yes & $313(3 \mid .9)$ & $380(37.3)$ & $693(34.7)$ & \\
\hline No & $668(68.1)$ & $639(62.7)$ & $1307(65.4)$ & \\
\hline
\end{tabular}


and $44.5 \%$ of rural residents were health literate. Only $34.0 \%$ of the participants purchased medication and $19.8 \%$ are currently smoking (Table 1).

In examining the information on lifestyle practices, typology of retirement planning, health advice and last visits to a medical doctor, there was a significant statistical association between the last visit to a medical doctor and the area of residence $(P<0.05)$. Urban residents were more likely to have visited a medical doctor in the last 35 months than rural residents. The latter, however, visited more in 36 years and beyond (Table 2). Almost 14 percent (13.7\%) of the participants indicated that they were unaware of the signs and symptoms of hypertension, and $24 \%$ were unaware of the signs and symptoms of diabetes mellitus (Table 3 ).

Forty-three percent of the participants self-reported being diagnosed with cancers such as prostate and colorectal in the last 6 months; $9.6 \%$ with hypertension; 5.3\% with heart disease, $5.3 \%$ with benign prostatic hyperplasia; $5.3 \%$ with diabetes mellitus; $3.8 \%$ with kidney/bladder problems and $27.4 \%$ did not specify the health condition(s). Fifty-two percent of participants sought medical attention immediately on the onset of illness; $42.3 \%$ stated 2-7 days after the onset of the illness; $34.2 \%$ took the medication as prescribed by their medical doctor; $25.4 \%$ knew the type of medication consumed; $57.9 \%$ of respondents indicated that good health denotes the absence of illness; as well as a state of mind (7.4\%) (Tables 4 and 5).

\section{Discussion}

This study demonstrated that health literacy is a very basic problem among the participants. Compared with the research by Montalto and Spiegler ${ }^{23}$ in which only $15 \%$ of the rural population studied experienced health literacy deficits, this research identified nearly half of the participants $(48.2 \%)$ with health literacy difficulties. Therefore, it is possible that some of the participants were unable to read words commonly used in health care. Words such as allergic, diagnosis, and inflammatory are extremely common and are critical to the effective self-management of many health problems. Inability to understand these common words can lead to detrimental health outcomes. Furthermore, patients are frequently given forms to complete asking if they have any allergies. Misreading this form could be life-threatening to the person

Table 2 The examination of variables such as medication compliance, visit to the medical doctor by area of residence

\begin{tabular}{|c|c|c|c|c|}
\hline \multirow[t]{2}{*}{ Variable } & \multicolumn{2}{|c|}{ Area of residence } & \multirow[t]{2}{*}{ Total } & \multirow[t]{2}{*}{$P$} \\
\hline & Urban & Rural & & \\
\hline Lifestyle practices & & & & 0.498 \\
\hline Smoking & $88(14.9)$ & $108(17.4)$ & $196(16.2)$ & \\
\hline Prostate cancer & $48(8.1)$ & $56(9.0)$ & $104(8.6)$ & \\
\hline Diet & $143(24.3)$ & $154(24.8)$ & $297(24.6)$ & \\
\hline Physical activity & $310(52.6)$ & $302(48.7)$ & $612(50.6)$ & \\
\hline Type of retirement plan & & & & 0.133 \\
\hline Finance & $8(2.0)$ & $19(4.5)$ & $27(3.3)$ & \\
\hline Social arrangement & $14(3.5)$ & $14(3.3)$ & $28(3.4)$ & \\
\hline Health care & $379(94.5)$ & $391(92.2)$ & $770(93.3)$ & \\
\hline Taking medication & & & & 0.225 \\
\hline No medication & $662(67.5)$ & $653(64.1)$ & $1315(65.8)$ & \\
\hline Cancer & $253(25.8)$ & $283(27.8)$ & $536(26.8)$ & \\
\hline Hypertension & $54(5.5)$ & $58(5.7)$ & $112(5.6)$ & \\
\hline Heart problems & $9(0.9)$ & I5 (I.5) & $24(1.2)$ & \\
\hline Benign prostatic hyperplasia & $3(0.3)$ & $8(0.8)$ & II (0.6) & \\
\hline Diabetes mellitus & $0(0.0)$ & $2(0.2)$ & $2(0.1)$ & \\
\hline Advice (or none) given & & & & 0.601 \\
\hline None & $582(59.3)$ & $583(57.2)$ & II 65 (58.3) & \\
\hline Smoking & $53(5.4)$ & $45(4.4)$ & $98(4.9)$ & \\
\hline Prostate cancer & $47(4.8)$ & $53(5.2)$ & $100(5.0)$ & \\
\hline Diet & $165(16.8)$ & $190(18.6)$ & $355(17.8)$ & \\
\hline Physical exercise & $134(13.7)$ & I48 (I4.5) & $282(14.1)$ & \\
\hline Last visit to doctor & & & & ${ }^{*} 0.021$ \\
\hline Less than 12 months & $148(32.0)$ & $|4|(3 \mid .2)$ & $289(31.6)$ & \\
\hline 12 to 35 months & $196(42.4)$ & $160(35.4)$ & $356(38.9)$ & \\
\hline 36 and beyond months & $118(25.5)$ & I5I (33.4) & $269(29.4)$ & \\
\hline
\end{tabular}

${ }^{*} P<0.05$. 
Table 3 Awareness of signs and symptoms of hypertension and diabetes mellitus

\begin{tabular}{|c|c|c|c|c|c|}
\hline \multirow[t]{2}{*}{ Signs and symptoms } & \multicolumn{2}{|c|}{ Hypertension } & \multirow[t]{2}{*}{ Signs and symptoms } & \multicolumn{2}{|c|}{ Diabetes mellitus } \\
\hline & $\mathbf{n}$ & $\%$ & & $\mathbf{n}$ & $\%$ \\
\hline- & - & - & Frequent urination & 232 & 11.6 \\
\hline Headache & 259 & 13.0 & Excessive thirst & 311 & 15.6 \\
\hline Dizziness & 272 & 13.6 & Excessive hunger & 187 & 9.4 \\
\hline Blurred vision & 538 & 26.9 & Unusual weight loss & 132 & 6.6 \\
\hline Nausea & 195 & 9.8 & Increased fatigue & 252 & 12.6 \\
\hline Swollen feet & 217 & 10.9 & Irritability & 106 & 5.3 \\
\hline Shortness of breath & 245 & 12.3 & Blurred vision & 301 & 15.1 \\
\hline Unaware & 274 & 13.7 & Unaware & 479 & 24.0 \\
\hline
\end{tabular}

who has a drug or treatment allergy, but fails to share that information as a result of an inability to recognize the printed word. Likewise, the word inflammatory is a common term used with many health care problems. Anti-inflammatory medications are prescribed for treatment of many conditions, and a lack of understanding of the word may lead to drug misuse. ${ }^{24}$

The majority of the participants indicated good selfrelated health status and most experienced good health status during their childhood; just over half of the participants viewed good health status as the absence of disease. In addition, the study also found that the majority of the elderly men had high cognitive functionality and low functional independence. However, the narrow understanding of health status held by these men ignored their quality of life, given their reported low functional independence. It is possible that the majority of these men were in intimate partner relationships and received social support from their partner, friends and relatives. Studies have shown that family, friends, and home health care workers may act as "surrogate readers" for individuals with inadequate literacy, and thus may mitigate the negative effects of inadequate literacy on patients' understanding of their medications and self-care instructions. ${ }^{25} \mathrm{In}$ contrast, individuals who are in average or above-average health may rely more on their own reading abilities to decipher medical instructions, and this may put them at risk for preventable hospitalizations. ${ }^{25}$

The problems of low health literacy may be especially acute for those who live in rural areas. Rural areas are characterized by residents with lower levels of education, higher rates of unemployment, lower salaries, and lack of health insurance ${ }^{26,27}$ The low level of health literacy becomes more evident with the significant statistical association found between health care-seeking behavior and area of residence, where more rural residents sought medical care, such as visits to primary health centers, hospitals or private medical institutions when they are ill, as compared with urban residents. However, more urban residents visited their medical doctors in the last 12 months, or 12-35 months compared with their rural counterparts. The finding that more rural residents sought medical care compared with urban residents is interesting, and could be due to the availability of more primary health centers in rural St Catherine compared with hospitals and other health centers in urban areas; rural men being more concerned about their health related problems, and the possibly higher prevalence of chronic disease. Our findings are not in accordance with other studies that have found that urban residents are more likely to seek medical care sooner than rural residents. ${ }^{28,29}$ This is because rural residents are culturally likely to delay seeking health care until a condition has become advanced or urgent, or until multiple chronic conditions exist. They then experience a relative shortage of health care sites and choices, a need to travel greater distances to reach health care, problems of transportation, and very probably, an explanation of a complicated treatment regimen to act upon..$^{29,30}$

The majority of residents in both residential locations did not seek medical attention when they were ill, and had not visited the doctor in the last 12 months. In addition, just over half of the participants sought medical attention immediately on the onset of illness, while approximately two-fifths stated 2-7 days after the onset of the illness. There may be practical or economic hindrances to accessing medical services. Furthermore, there may be other factors such as long hours of traveling time, waiting time, costs, and work or family obligations. Health care in Jamaica is free to all citizens and legal residents at government hospitals and clinics. This includes prescription drugs. However one of the drawbacks to free health care is the presence of long lines with no appointments accepted by the physicians. In addition, some rural and urban public hospital and clinics are without their full cadre of medical doctors and other health care practitioners. The long lines and waiting times experienced by some of the participants at these public health care institutions may have 
Table 4 Self-reported diagnosed health conditions

\begin{tabular}{|c|c|c|c|c|c|c|c|}
\hline \multirow[t]{2}{*}{ Details } & I-6 months & $7-12$ months & $2-5$ years & $6-10$ years & I I-20 years & $2 I-30$ years & $30+$ years \\
\hline & n (\%) & n (\%) & n (\%) & n (\%) & n (\%) & n (\%) & n (\%) \\
\hline Cancer & $180(43.3)$ & $105(4 \mid .5)$ & $36(17.1)$ & $12(7.5)$ & $3(2.9)$ & $\mathrm{I}(\mathrm{I} .6)$ & $\mathrm{I}(4.8)$ \\
\hline Hypertension & $40(9.6)$ & $27(10.7)$ & $32(15.2)$ & $33(20.6)$ & - & $8(13.1)$ & $2(9.5)$ \\
\hline Heart disease & $22(5.3)$ & $24(9.5)$ & $10(4.7)$ & $25(15.6)$ & $17(16.7)$ & $6(9.8)$ & $\mathrm{I}(4.8)$ \\
\hline Benign prostatic hyperplasia & $22(5.3)$ & $18(7.1)$ & $29(13.7)$ & $29(18.1)$ & $24(23.5)$ & I3 (2I.3) & $7(33.3)$ \\
\hline Diabetes mellitus & $22(5.3)$ & $18(7.1)$ & $33(15.6)$ & $12(7.5)$ & $25(24.5)$ & $14(23.0)$ & $5(23.8)$ \\
\hline Kidney/Bladder diseases & $16(3.8)$ & $60(23.7)$ & $71(33.6)$ & $49(30.6)$ & $33(32.4)$ & $19(31.2)$ & $5(23.8)$ \\
\hline Unspecified & $114(27.4)$ & I (0.4) & $(0.0)$ & $(0.0)$ & $(0.0)$ & $(0.0)$ & $(0.0)$ \\
\hline Total & 416 & 253 & 211 & 160 & 102 & 61 & 21 \\
\hline
\end{tabular}

contributed to their dissatisfaction with the quality of health care offered by the state, and deterred them from readily visiting their institutions for medical care. This may be one of the factors, which account for the low health-seeking behavior of the participants in this study, a fact that is consistent with reports from other developing countries. ${ }^{31}$

Cultural factors influence a person's decision to seek medical help. Strong social ties and cultural traditions could provide a reservoir of lay knowledge that can be used instead of professional services. ${ }^{32}$ In this study one-tenth of the respondents used home remedies. Furthermore, employment may be a contributing factor to the low health-seeking behavior of the participants in the study, as only one-quarter of the participants were employed and almost nine-tenths were heads of their households. These factors may reduce the amount of resources available to these men in order for them to seek medical care when they become ill. The literature suggests that people with fewer resources have lower health literacy than people with more resources. ${ }^{11}$

One of the most obvious and critical areas where low literacy skills can have a direct effect on a person's health is the failure to understand and comply with the use of prescription drugs. ${ }^{33,34}$ While medication noncompliance among patients occurs at all age levels, the reasons for noncompliance differ across the life course. The problem is more evident among elderly patients since they are more likely to use medication and take several drugs simultaneously; they may become confused or misunderstand the proper dosage, fail to comply intentionally because of the cost or side effects, or otherwise fail to follow instructions because of an increased sensitivity to drug effects..$^{33}$ In this study approximately one-third of the participants were taking medication for different chronic diseases including cancer, hypertension, diabetes mellitus and cardiovascular conditions. Of these patients, noncompliance was approximately one-third and only one-quarter knew the name, or had any information on the medications they were taking. Low health literacy lowers health-seeking behaviors and medication compliance. This leads to adverse health outcomes. ${ }^{35}$
The combination of low literacy and chronic illness is particularly common among the elderly. ${ }^{36}$ In 1999, cardiovascular diseases were the leading cause of hospital admissions among persons 60 and older in Jamaica, followed by diabetes mellitus. The leading cause of hospital deaths in 1999 was cardiovascular disease, followed by diseases of the respiratory system. In 2000, persons aged 60 years and older accounted for $9.7 \%$ of the population. The main noncommunicable diseases affecting the elderly were hypertension, arthritis, overweight, and diabetes mellitus. ${ }^{37}$ Furthermore, inadequate health literacy (eg, the inability to read and comprehend basic health-related materials such as prescription bottles and appointment slips) is associated with less knowledge among patients with chronic diseases, worse self-management skills, and lower use of preventive services..$^{38,39}$ The low health literacy among the men in this study may contribute to less control of their chronic diseases, as people with inadequate health literacy are less knowledgeable about their chronic diseases than people with high health literacy. ${ }^{14}$ Another key finding is the low awareness among the participants of the symptoms of diabetes and hypertension, two of the main noncommunicable diseases among the elderly in Jamaica. Only about one-seventh to one-quarter of the elderly men knew the symptoms of diabetes mellitus and hypertension.

The lack of awareness of the symptoms of these two diseases may be explained by the finding that the majority of the participants only received primary school education. This finding corroborates the finding in the literature, which postulates that level of education predicted $36 \%$ and $26 \%$ respectively of the variance in general context numeracy and health context numeracy among older adults. Moreover, people who completed high school have greater health literacy than people who did not complete high school. ${ }^{9}$ Furthermore, low health literacy in elderly men may affect the management of their diseases and overall quality of life. Nurss ${ }^{40}$ compared the health literacy of people with hypertension and diabetes to knowledge about the disease, and found that only around half of those with inadequate 
Table 5 Heath related issues that affected the elderly men

\begin{tabular}{|c|c|c|}
\hline Characteristic & $\mathbf{n}$ & $\%$ \\
\hline \multicolumn{3}{|c|}{ Seeking medical advice (outside of illness) } \\
\hline Yes & 157 & 7.9 \\
\hline No & 1843 & 92.2 \\
\hline \multicolumn{3}{|c|}{ Meaning of good health } \\
\hline Physically well (not sick) & 567 & 57.9 \\
\hline Healthy diet & 190 & 19.4 \\
\hline Self-care & 96 & 9.8 \\
\hline Religious activity & 40 & 4.1 \\
\hline State of mind & 73 & 7.4 \\
\hline Physical functioning & 14 & 1.4 \\
\hline \multicolumn{3}{|c|}{ Factors responsible for one's ill-health or good health } \\
\hline Diet & 327 & 16.4 \\
\hline Exercise & 134 & 6.7 \\
\hline Sleep & 75 & 3.8 \\
\hline Age & 44 & 2.2 \\
\hline Religion & 22 & I.I \\
\hline No chronic disease & 13 & 0.7 \\
\hline Regular checkup & 29 & 1.5 \\
\hline Family life & 12 & 0.6 \\
\hline Self-care & 20 & 1.0 \\
\hline Financial status & 6 & 0.3 \\
\hline Mobility & 5 & 0.3 \\
\hline Nonresponse & 1313 & 65.7 \\
\hline \multicolumn{3}{|c|}{ Took medication as prescribed by medical practitioner } \\
\hline Yes & 685 & 34.2 \\
\hline No & 1315 & 65.8 \\
\hline \multicolumn{3}{|c|}{ Name and nature of taken medication } \\
\hline Known & 509 & 25.4 \\
\hline Unknown & 1491 & 74.6 \\
\hline \multicolumn{3}{|c|}{ Length of time before seeking medical attention } \\
\hline Immediately & 1041 & 52.1 \\
\hline $2-7$ days & 825 & 41.3 \\
\hline I-3 weeks & 36 & 1.8 \\
\hline 4 weeks-I month & 17 & 0.9 \\
\hline Don't go & 14 & 0.7 \\
\hline Wait & 67 & 3.4 \\
\hline
\end{tabular}

health literacy knew the important clinical signs required for disease self-management. Glycemic control was worse for people with diabetes and health literacy problems according to Schillinger et al. ${ }^{41}$ The combination of inadequate health literacy and chronic illnesses, such as diabetes mellitus, reduces the likelihood that people will participate in their care to the extent needed for effective disease management. ${ }^{42}$

People of low health literacy are neither unintelligent nor unmotivated..$^{43}$ Although reticent to ask for assistance because of shame and embarrassment, ${ }^{40}$ those who struggle with literacy do have the ability to learn, if appropriate explanations are given or if patient education materials are presented at their level. Approximately one-third of the participants reported that they did not receive any advice from the medical doctor on their last visit to the hospital and/or clinic, while the others got advice on a number of diseases such as prostate cancer, hypertension and diabetes mellitus. A number of factors may have contributed to this finding, which could include the time that the medical doctor spent with the participant; whether the patient asked the medical doctor for advice, and the patient's ability to communicate with the medical doctor. In medical care settings, a patient's oral language skills are related to his or her ability to describe symptoms and can subsequently affect the practitioner's ability to diagnose. For example, studies have indicated that a physician's assessment of a patient's health history, or the test of a patient for dementia, may be affected by the patient's literacy status. ${ }^{44}$ Furthermore, the patient's oral comprehension abilities may curtail his or her dialogue with the physician, or ability to comprehend oral instructions. This may contribute to delayed diagnosis of many of the medical conditions indicated by the participants in this study. In this study just over one quarter of the participants were diagnosed with cancers such as prostate and colorectal in the past 1-6 months. Approximately one-tenth, were diagnosed with hypertension and one-twentieth with heart disease and diabetes mellitus.

Morbidity and mortality data over the last three decades highlighted prostate cancer as the most commonly diagnosed malignancy in Jamaican males. The cancer registry in Jamaica records incident cases of cancer in the parishes of Kingston and St Andrew where approximately 27\% of the island's population of 2.5 million residents lives. ${ }^{45}$ Information on cancer-related deaths showed prostate cancer to be the leading cancer site among males $(30.3 \%)$ and the leading cause of cancer mortality in Jamaica (16.5\% of total cancer deaths). ${ }^{46}$ Bennett and associates ${ }^{47}$ assessed the relationship of literacy, race, and stage of presentation among patients diagnosed with prostate cancer. The focus of the study was 212 low-income men from two prostate cancer clinics. The authors report that men with literacy levels below sixth grade were more likely to present with advanced-stage prostate cancer. They conclude that low literacy may be an overlooked but significant barrier to the diagnosis of early-stage prostate cancer among low-income white and black men. They suggest that the development of culturally sensitive, low-literacy educational materials may improve patient awareness of prostate cancer and the frequency of diagnosis at early stages. Thus it is possible that the low health literacy rate contributes to the high number of participants diagnosed with cancer during the past 1-6 months, in particular prostate cancer. However, there is no information in this study or in the literature as to the number of men in Jamaica diagnosed with advanced prostate cancer. 
Health literate individuals have the knowledge and ability to make healthy choices and adopt healthy lifestyles. They employ health skills, which are a subset of their life skills. The elderly have the greatest health literacy needs due to their high prevalence of chronic diseases, yet they are disproportionately represented among the health illiterate. ${ }^{48,49}$ Preventive strategies can in fact improve the health of the ageing population by bringing benefits to major health conditions like obesity, diabetes mellitus, cardiovascular disease and osteoporosis. Such measures can help both to improve the quality of life of older people as well as contribute to the control of health care costs. In this study approximately two-thirds of the participants reported being engaged in some form of physical activity; however some were also engaged in adverse lifestyle practices, as nearly one-fifth of the participants were currently smokers. Evidence from other research confirms this, by showing that the benefit of moderate exercise can help in improving arthritis-related and other chronic illnesses such as diabetes mellitus and heart diseases. ${ }^{51}$ Indeed, physical activity plays a central role in the prevention and management of chronic disease, ${ }^{52}$ and physical inactivity is identified as a leading cause of disability among older adults. ${ }^{53}$ Even failure to walk for exercise, for example, is shown to be an important risk factor for illness in old age. ${ }^{54}$

This article has made a significant contribution to the literature by highlighting and linking health literacy, healthseeking behavior and lifestyle practices among men in Jamaica. This subject area is under-researched in Jamaica and the wider English-Speaking Caribbean. However, there are some limitations to this study. Women $55+$ years were not a part of our sample, and so the study cannot be generalized about Jamaicans. However, it may be generalized for men 55 years and older. In addition, there is the possibility of social desirability bias, where the participants in the study told the interviewers what they wanted to hear to get their approval.

\section{Conclusion}

This study demonstrated that health literacy is a very basic problem among elderly men in Jamaica. The majority of the participants reported good current health status and high cognitive functionality but low functional independence. A significant number of the respondents did not take their prescribed medication, nor did they seek medical attention despite having reported prostate cancer and number of other chronic diseases. These findings point to low health literacy among elderly men, which requires urgent programmatic attention from the Ministry of Health to reduce adverse health outcomes in the country. This study also provides invaluable information on men that is far-reaching and can be used to guide in the formulation of health policies and intervention programs.

\section{Disclosures}

The authors have no competing interests to report.

\section{References}

1. Statistical Institute of Jamaica. Available from:http://statinja.com/stats. html. Accessed Mar 25, 2010.

2. Eldemire D. An Epidemiological Study of the Jamaican Elderly. $\mathrm{PhD}$ Thesis. Trinidad, Jamaica: The University of the West Indies; 2003.

3. Plan of Action on Health and Ageing. Older Adults in the Americas, 1992-2000. Washington, DC;PAHO; 1999.

4. King H, Aubert RE, Herman WH. Global burden of diabetes, 1995-2025: prevalence, numerical estimates, and projections. Diabetes Care. 1998;21:1414-1431.

5. Murray CL, Lopez A. The Global Burden of Disease. Geneva, Switzerland:World Health Organization; 1996.

6. Thobaben M. Health literacy and elderly home health clients. Home Health Manage Prac. 2007;19:478-479.

7. Levin-Zamir D, Peterburg Y. Health literacy in health systems: perspectives on patient self-management in Israel. Health Promot Int. 2001;16:87-94.

8. Miller MJ, Degenholtz HB, Gazmararian JA, et al. Identifying elderly at greater risk of inadequate health literacy: A predictive model for population-health decision makers. Res Soc Adm Pharm. 2007;3:70-85.

9. Donelle L, Hoffman-Goetz L, and Arocha JF. Assessing health numeracy among community- dwelling older adults. J Health Commun. 2007;12:651-665.

10. Parikh NS, Parker RM, Nurss JR, et al. Shame and health literacy: The unspoken connection. Patient Educ Couns. 1996;27:33-39.

11. Howard DH, Sentell T, Gazmararian JA. Impact of health literacy on socioeconomic and racial differences in health in an elderly population. J Gen Intern Med. 2006;21:857-861.

12. Baker DW, Gazmararian JA, Sudano J, et al. The association between age and health literacy among elderly persons. J Gerontol. 2000;55B:S368-S374.

13. Zanchetta MS, Perreault M, Kaszap M, et al. Patterns in information strategies used by older men to understand and deal with prostate cancer: An application of the modelisation qualitative research design. Int $J$ Nurs Stud. 2007;44:961-972.

14. Gazmararian JA, Williams MV, Peel J, et al. Health literacy and knowledge of chronic disease. Patient Educ Couns. 2003;51: 267-275.

15. Wolf MS, Gazmararian JA, Baker DW. Health literacy and health risk behaviors among older adults. Am J Prevent Med. 2007;32:19-24.

16. Cho YI, Lee SY D, Arozullah AM, et al. Effects of health literacy on health status and health service utilization among the elderly. Soci Sci Med. 2008;66:1809-1816.

17. Hanchate AD, Ash AS, Gazmararian JA, et al. The demographic assessment for health literacy (DAHL): A new tool for estimating associations between health literacy and outcomes in national surveys. J Gen Intern Med. 2008;23:1561-1566.

18. Kickbusch IS. Health literacy: Addressing the health and education divide. Health Promot Int. 2001;16:289-297.

19. Ibrahim SY, Reid F, Shaw A, et al. Validation of a health literacy screening tool (REALM) in a UK population with coronary heart disease. J Public Health (Oxf). 2008;30(4):449-455.

20. Von Wagner C, Knight K, Steptoe A, et al. Research Report. Functional health literacy and health-promoting behaviour in a national sample of British adults. J Epidemiol Community Health. 2007;61:1086-1090. 
21. Van Servellen G, Brown JS, Lombardi E, et al. Health literacy in low-income Latino men and women receiving antiretroviral therapy in community-based treatment centers. AIDS Patient Care STDS. 2003; 17(6):283-298.

22. Cohen L, Holliday M. Statistics for Social Sciences. London, UK: Harper and Row; 1982.

23. Montalto NJ, Spiegler GE. Functional health literacy in adults in a rural community health center. $W V$ Med J. 2001;97(2):111-114.

24. Davis T, Wolf M. Health Literacy: Implications for family medicine. Fam Med. 2004;36(8):595-598.

25. Williams MV, Baker DW, Parker RM, et al. Relationship of functional health literacy to patients' knowledge of their chronic disease: A study of patients with hypertension and diabetes. Arch Intern Med. 1998;158(2):166-172.

26. Ricketts TC. Rural Health in the United States. New York Ny: Oxford University Press; 1999.

27. Gamm LD, Hutchison LL, Dabney BJ, et al. Rural Healthy People 2010: A Companion Document to Healthy People 2010. Vol. 1. College Station, TX: The Texas A\&M University System Health Science Center, School of Rural Public Health, Southwest Rural Health Research Center; 2003.

28. Casey M. Are rural residents less likely to obtain recommended preventive healthcare services? Am J Prev Med. 2001;21(3):182-188.

29. Eberhardt MS, Ingram DD, Makuc DM, et al. Urban and Rural Health Chartbook. Health, United States, Hyattsville, MD: National Center for Health Statistics; 2001.

30. Doak CC, Doak LG, Root JH. Teaching Patients with Low Literacy Skills (2nd ed.). Philadelphia, PA: Lippincott; 1996.

31. Bernhart MH, Wiadnyana IG, Wihardjo H, et al. Patient satisfaction in developing countries. Soc Sci Med. 1999;48:989-996.

32. Berkanovic E, Telesky MA, and Reeder S. Structural and social psychological factors in the decision to seek medical care for symptoms. Med Care. 1981;7:693-709.

33. Salzman C. Medication compliance in the elderly. J Clin Psychiatry. 1995;56(1):18-23.

34. Murphy PW, Davis TC, Jackson RH, et al. Effects of literacy on healthcare of the aged: Implications for health professionals. Educ Gerontol. 1993;19(4):311-316.

35. Hussey LC. Overcoming the clinical barriers of low literacy and medication non-compliance among the elderly. J Gerontol Nurs. 1991;17:27-29.

36. Davis, TC, Meldrum H, Tippy PK, et al. How poor literacy leads to poor health care. Patient Care. 1996;15:94-127.
37. Country Health Profile - PAHO/WHO - OPS/OMS. 2010. Available from http://www.paho.org/English/DD/AIS/cp_388.htm

38. Gazmararian JA, Williams MV, Peel J, et al. Health literacy and knowledge of chronic disease. Patient Educ Couns. 2003;51(3):267-275.

39. Scott TL, Gazmararian JA, Williams MV, et al. Health literacy and preventive health care use among Medicare enrollees in a managed care organization. Med Care. 2002;40(5):395-404.

40. Nurss JR, El-Kebbi IM, Gallina DL, et al. Diabetes in urban African Americans: Functional health literacy of municipal hospital outpatients with diabetes. Diabetes Educ. 1997;23:563-568.

41. Schillinger D, Grumbach K, Piette J, et al. Association of health literacy with diabetes outcomes. JAMA. 2002;288:475-482.

42. Chwedyk P. Vital signs: Diabetes health literacy board hopes to close patient education gaps. Minor Nurse Newsh. 2003:9.

43. Cheatham JB. TUTOR: A Collaborative Approach to Literacy Instruction. Syracuse, NY: Literacy Volunteers of America Inc. 1993.

44. Weiss BD, Coyne C. Communicating with patients who cannot read. $N$ Engl J Med. 1997;337(4):272-274.

45. The Statistical Institute of Jamaica. Demographic Statistics 2000. Kingston, Jamaica: The Statistical Institute of Jamaica; 2001.

46. Blake G, Hanchard B, Mitchell K, et al. Jamaica cancer mortality statistics, 1999. West Indian Med J. 2002;51:64-67.

47. Bennett C L, Ferreira MR, Davis TC, et al. Relation between literacy, race, and stage of presentation among low-income patients with prostate cancer. J Clin Oncol. 1998;16:3101-3104.

48. Parker R. Health literacy: a challenge for American patients and their health care providers. Health Promot In. 2000; 15(4):277-283.

49. Nielsen-Bohlman L, Panzer AM, Kindig D A, Editors. Health Literacy: A Prescription to End Confusion, Washington, $B C$; National Academy of Sciences; 2003.

50. Byrne D. Prevention key to healthcare costs in an ageing society. Speech given at the Informal Health Council in Noordwjk on 2004 Sep 10.

51. Rafei UM. Strengthening the Foundations of Health in South-East Asia. Vol. II: 1997-2000. New Delhi, India: World Health Organization; 2004.

52. Cyarto EV, Moorhead GE, and Brown WJ. Updating the evidence relating to physical activity intervention studies in older people. $J \mathrm{Sci}$ Med Sport. 2004;7:30-38

53. Buchner DM. Physical activity and quality of life in older adults. JAMA. 1997;277:64-66.

54. Strawbridge W, Cohen R, Shema S, et al. Successful dying: predictors and associated activities. Epidemiology. 1996;144:135-141.
Patient Related Outcome Measures

\section{Publish your work in this journal}

Patient Related Outcome Measures is an international, peer-reviewed, open access journal focusing on treatment outcomes specifically relevant to patients. All aspects of patient care are addressed within the journal and practitioners from all disciplines are invited to submit their work as well as healthcare researchers and patient support groups. Areas covered will

\section{Dovepress}

include: Quality of life scores; Patient satisfaction audits; Treatment outcomes that focus on the patient; Research into improving patient outcomes; Hypotheses of interventions to improve outcomes; Short communications that illustrate improved outcomes; Case reports or series that show an improved patient experience; Patient journey descriptions or research. 